\title{
RECUPERAR AS FINANÇAS PÚBLICAS EM FRANGALHOS É O DESAFIO PARA 2018
}

Coluna publicada em 6.2.2018: <https://www.conjur.com.br/2018-fev-06/ contas-vista-recuperar-financas-publicas-frangalhos-desafio-2018>

O ano de 2018 começou com más notícias no campo das finanças públicas. Estados e municípios indo à falência, sucumbindo às dívidas impagáveis, com poucas perspectivas de solução. Os efeitos cada vez mais se fazendo sentir no dia a dia, com salários de servidores públicos em atraso, fornecedores sem receber pelos serviços prestados, e os serviços públicos ainda mais deficientes em razão da escassez de recursos.

Uma "bomba" que agora explode, mas não sem aviso prévio...

Desde a retomada do equilíbrio das contas públicas, que se iniciou em meados da década de 1990, com a implantação da moeda real em 1994, e a Lei de Responsabilidade Fiscal, em 2000, houve uma grande evolução em nossas contas públicas, com aperfeiçoamentos nos sistemas de contabilidade pública, qualidade do gasto, fiscalização e controle da atividade financeira do setor público.

Uma evolução que precisa continuar avançando, mas que, infelizmente, a partir do final da década de 2000, foi sendo gradativamente abandonada, em um retrocesso inaceitável, cujo resultado não poderia ter sido outro. Uma decorrência do desrespeito às normas de gestão fiscal responsável, que, ao invés de serem respeitadas, passaram a ser "contornadas" por mecanismos de "contabilidade criativa" que foram se disseminando por todo o setor público. Um mau exemplo que veio "de cima", dadas as várias manobras que se observaram no âmbito do governo federal e que, somadas à leniência dos órgãos de fiscalização, se espalharam por toda a federação.

Espera-se que o recente impeachment da presidente tenha sido o exemplo necessário e suficiente para dar a merecida lição aos gestores públicos que ousam 
desrespeitar os princípios da gestão fiscal responsável. Mas é importante continuarmos atentos.

Os princípios que nortearam a Lei de Responsabilidade Fiscal, voltados a promover uma gestão pública responsável, em que se destacam especialmente o planejamento, a limitação das despesas e a transparência, são os pilares que dão a base para um desenvolvimento seguro e sustentável. Descumpri-los é, além de violação ao ordenamento jurídico vigente, uma atitude verdadeiramente suicida, pois as consequências são inexoráveis, como está se vendo.

É por essa razão que temos de ser firmes na defesa desses princípios, repudiando todas e quaisquer ameaças que venham a sofrer, como ocorreu recentemente, logo ao iniciar este ano de 2018, que, tudo indica, não será fácil para as finanças públicas. O anúncio da intenção de modificar e "flexibilizar" a "regra de ouro" em nada colaborou para a defesa desses valores. ${ }^{1}$

A dívida pública é o verdadeiro "calcanhar de Aquiles" das finanças públicas. Tema delicado, pouco estudado e compreendido, ${ }^{2}$ mas fundamental para a gestão financeira saudável e responsável.

Tão relevante que é uma das poucas normas de responsabilidade fiscal que está presente no texto constitucional. A chamada "regra de ouro" das finanças públicas está positivada no artigo 167, III, da Constituição.

Uma norma de limitação da dívida que ganhou grande visibilidade, ante as notícias divulgadas do interesse em alterá-la, mitigando seus efeitos, como já mencionado há pouco.

Tal como expressa o artigo 167, III, da Constituição, são vedadas as operações de crédito que ultrapassem o montante das despesas de capital, ressalvadas as autorizadas por créditos suplementares ou especiais específicos, aprovados pelo Poder Legislativo por maioria absoluta. A finalidade dessa norma é proibir que, em cada ano, contraia-se dívida em volume superior ao das despesas de capital (basicamente investimentos e amortização da dívida pública). Isso porque, logicamente, operações de crédito em quantidade maior do que as despesas de capital significariam sua utilização para cobrir despesas correntes: um claro sinal de descontrole das contas.

1 "Regra de ouro tem de ser revista para 2019, afirma Dyogo" (entrevista do ministro do Planejamento Dyogo de Oliveira aos repórteres Fábio Graner e Edna Simão), Valor Econômico, 8 de janeiro de 2018; "Governo prepara PEC para muda "regra de ouro" do gasto público", Folha de S.Paulo, 23 de janeiro de 2018.

2 Devo, não nego: o Direito Financeiro e o dilema da dívida pública, nesta edição, p. 455-460. 
Mas por que, afinal, a dívida não poderia ser utilizada para atender despesas de manutenção da máquina pública, como salários, aposentadorias, pensões e compras de material de consumo? A resposta é bastante simples: são despesas permanentes, constantes, dificilmente reduzíveis, do setor público. Algumas delas, aliás, tendem a crescer quase que automaticamente, como as despesas previdenciárias, em razão do envelhecimento da população. Raramente retrocedem, ao menos no curto prazo: seu ajuste exige adaptaçóes da administração que demoram a surtir efeitos. Os recursos de empréstimos, ao contrário, entram em caráter provisório nos cofres públicos e, cedo ou tarde, devem ser restituídos ao credor. Fica claro, portanto, que as contas públicas estão desajustadas quando, para pagar até mesmo as despesas necessárias ao seu funcionamento, o setor público necessite de empréstimos.

As despesas de capital, por outro lado, têm outras características. Como normalmente concorrem para a formação de bens de capital, expandem a atividade e aumentam a capacidade de prestação de serviços públicos. São exemplos as compras de máquinas e equipamentos, a realização de obras públicas, os aumentos de participação acionária do Estado, dentre outros. Benefícios, portanto, que vão além da simples manutenção da máquina administrativa, porque contribuem para sua expansão. Nesse caso, pode ser interessante o acesso do Estado a recursos que não estão no seu orçamento, obtendo-os da poupança disponível para o crédito. É até medida de equidade entre as gerações: se os benefícios são de longo prazo, que os custos não sejam todos arcados pelas geraçóes presentes (como o seriam caso se optasse pela tributação como forma exclusiva de financiamento das despesas de capital), mas também pelas futuras.

Sendo esse o caso, deve-se reconhecer que há muitas vantagens em evitar o descontrole das contas públicas, limitando o total das operações de crédito de um exercício ao volume das despesas de capital. E, caso seja necessário excepcionalmente ultrapassá-lo, que haja autorização legislativa específica, tal como dispõe o atual artigo 167, III, da Constituição, na sua parte final.

Mas seria a "regra de ouro" uma previsão recente, criada pela Constituição de 1988 e aplicada exclusivamente em razão dela? Não é bem o caso, ainda que seja inegável que a previsão constitucional dessa regra lhe confira grande importância e a insira na sistemática de controle jurídico-financeiro da administração. Como defendeu Júlio Marcelo de Oliveira em recente coluna aqui no ConJur sobre o tema, seria grave retrocesso sua exclusão do texto constitucional. ${ }^{3}$ Mas a

3 Flexibilizar regra de ouro será grave retrocesso nas contas públicas, publicada em 16 de janeiro de 2018. 
sua eventual revogação ou mitigação (possibilidade já explicitamente afastada pelo governo federal e pelo Congresso Nacional) não teria o condão de tornar a dívida pública sustentável, e obviamente não criaria dinheiro para pagar o imenso déficit público. Para avaliar a sustentabilidade da dívida pública e o risco de crédito do Brasil, o critério da "regra de ouro" continuaria a funcionar como um critério, dentre outros, a ser aplicado por todos aqueles que acompanham o estado das contas públicas. Uma dívida excessiva é uma dívida excessiva, e quebrar o termômetro não aplaca a febre - para mais uma vez recorrer aos precisos comentários de Júlio Marcelo sobre o tema. ${ }^{4}$

A ideia da "regra de ouro" já faz parte do patrimônio incorporado à teoria das finanças públicas. Embora não se identifique completamente com ela, remete à "regra fundamental" do economista alemão Adolph Wagner, segundo a qual os empréstimos deveriam servir apenas às despesas extraordinárias, e transformou-se para chegar ao ponto em que atualmente se encontra, associada às despesas de capital. De um lado, significou um avanço em relação às opiniōes que rejeitavam completamente a dívida pública, pois já se viu que a dívida pode ser uma forma eficiente de obtenção de recursos, caso seja utilizada para a formação do capital público. De outro, expõe a necessidade de racionalização do endividamento, de forma a evitar que seja mal-empregada. Na mesma corrente, disse Lorenz von Stein que "um Estado sem dívida ou faz muito pouco pelo seu futuro, ou exige demais do seu presente". 5 questão é como controlá-la, finalidade a que se presta a "regra de ouro" constitucional e todas as análises feitas a respeito da trajetória do endividamento público.

"Uma regra que vale ouro", como bem sintetizado pelo senador José Serra recentemente, ${ }^{6}$ sendo inaceitável sua alteração, e bem fez a opinião pública em manifestar rejeição a essa má proposta que inaugurou o ano e conseguiu, ao menos momentaneamente, tirá-la da agenda político-legislativa.

Novamente, como já mencionado em outras colunas, volta-se à questão de não se constatar haver o devido foco nas questões realmente estruturais, como a melhor gestão da máquina pública, ${ }^{7}$ que precisa ser modernizada, aplicando-se as

4 "Suspender a regra de ouro é quebra o termômetro da febre". O Estado de S.Paulo, 7 de janeiro de 2018.

5 As referências históricas à evolução da regra de ouro podem ser encontradas em LOCHAGIN, Gabriel; DOMINGUES, Juliana. O sistema de integração das normas constitucionais de limitação ao endividamento público. Revista Justiça do Direito, Passo Fundo, v. 31, n. 3, p. 564-565.

6 "Uma regra que vale ouro". O Estado de S.Paulo, 11 de janeiro de 2018.

7 Entre outros textos, Não falta dinheiro à administração pública, falta gestão, nesta edição, p. 255-258. 
modernas técnicas de inovação do setor público, com melhor aproveitamento dos recursos, fazendo mais com menos. E se for para aperfeiçoar o ordenamento jurídico, que se dê andamento aos projetos voltados a substituir a já cinquentenária Lei 4.320/1964, voltados a implantar a "lei de qualidade fiscal", modernizando as formas de elaboração e execução dos orçamentos públicos. ${ }^{8}$ O Direito Financeiro e a sociedade brasileira agradecem.

É preciso tomar medidas voltadas a um melhor controle e aproveitamento dos recursos públicos, o que abrange a reforma da Previdência, ${ }^{9}$ a regulamentação dos benefícios fiscais, das transferências voluntárias, e tantas outras formas pelas quais se veem os escassos recursos públicos escoarem pelo ralo. E que não são fáceis de aprovar e implementar, nem do agrado dos políticos, especialmente em ano de eleições. Sem esquecer as perdas decorrentes da corrupção e desvios dessa natureza.

Mas somente assim será possível dar início a uma urgente e imprescindível recuperação da confiança no setor público e a consequente retomada do crescimento do país, com o natural ajuste das contas públicas, com menos efeitos nocivos à sociedade.

E pôr um fim às medidas de "administração-bombeiro", tantas vezes combatidas nessas colunas, ${ }^{10}$ como, entre tantas outras, a Lei Complementar 156, de 2016 (Plano de Auxílio aos Estados com medidas para reequilíbrio fiscal), ${ }^{11}$ a Lei de Recuperação Fiscal (Lei Complementar 159, que institui o regime de recuperação fiscal dos Estados) ${ }^{12}$ cujas finalidades são voltadas tão somente a resolver problemas momentâneos, "apagando incêndios" que não vão deixar de voltar a aparecer pela frente. As circunstâncias atuais mostram que as labaredas já estão atingindo nossas casas!

8 Responsabilidade orçamentária precisa de melhorias, nesta edição, p. 255-258.

9 É preciso ter cautela e transparência para debater a reforma da Previdência, nesta edição, p. 269-274.

10 Que venha 2017, e traga boas noticias para o Direito Financeiro, nesta edição, p. 275-280.

11 Refinanciar dividas nada mais é do que postergar problemas, nesta edição, p. 433-438.

12 Um salve pela recuperação financeira do estado do Rio de Janeiro!, nesta edição, p. 449-454. 
